\title{
CLUSTERING OF THE ECONOMY AS A MEANS OF DEVELOPING AN INNOVATION INFRASTRUCTURE
}

\author{
Anna Kniazevych ${ }^{1}$, Volodymyr Olikhovskyi ${ }^{2}$, Marta Olikhovska ${ }^{3}$
}

\begin{abstract}
The experience of the functioning of national innovation systems in the developed countries indicates that the development of an innovative model of the national economy is impossible without the formation of an active innovation infrastructure. The article deals with the problems of formation and development of the innovation infrastructure of the country in difficult social and economic conditions based on clustering of the economy. The purpose of the research is to analyze the role and impact of clusters on self-organization and selfdevelopment of the country's innovation infrastructure in the conditions of limited financial resources. The research investigates the tendencies of the spread of regional clustering and its influence on the creation of a network of infrastructure companies, which, on a commercial basis, offer and distribute services. Clustering of regions is accompanied by the spread of the impact of a growing number of clusters (innovation structures of the network type) on the national economy and its innovation infrastructure. A certain infrastructural environment develops around the hub and the core of the cluster. It includes a number of companies specializing in innovative services, which can offer their services on a commercial basis not only to companies in this cluster, but also to all nearby innovative enterprises. The spread of clustering in all regions can serve as a basis for further self-organization and self-development of subsidiary companies under the influence of market mechanisms of management and growth of the innovation infrastructure of clusters into a basic platform of the innovation infrastructure of the country. Activation of entrepreneurship in clusters is carried out through the concentration of business activity and intersectoral cooperation. Vertical cluster associations are formed based on the synergy of enterprises, institutions, organizations, and individuals that are heterogeneous in the field of activity and form of ownership. The state, creating a favorable innovation environment, regulates the boundary conditions for innovation infrastructure subjects and clusters, which independently self-organize themselves under the influence of market mechanisms and expand their services to all regions, forming a holistic innovation infrastructure of the country.
\end{abstract}

Key words: innovation infrastructure, clustering of the economy, cluster, hub, network structures, self-organization, synergistic effect.

JEL Classification: $010,031,032$

\section{Introduction}

Since the second half of the twentieth century, the priority direction of the world economy development has been the widespread introduction of innovations in all spheres of production and economic activity. The activity of the country's innovation system for the introduction of the latest scientific and technical developments in the production and service spheres is the main factor in increasing the competitiveness of its products on the world market. The formation of the innovation system involves a set of special tools and appropriate means, which include legal regulations and a respective infrastructure for innovation activity.

Clustering is one of the most effective forms of organizing innovation processes. Support and development of clustering of the economy contributes to the emergence of a synergistic effect, which is necessary for the restoration, self-organization and

\footnotetext{
Corresponding author:

${ }^{1}$ Stepan Demianchuk International University of Economics and Humanities, Ukraine.

E-mail: kniazevich.a@gmail.com

ORCID: https://orcid.org/0000-0002-5394-5599

${ }^{2}$ Lviv Polytechnic National University, Ukraine.

E-mail: volodymyr.y.olikhovskyi@lpnu.ua

ORCID: https://orcid.org/0000-0002-4651-3835

${ }^{3}$ Lviv Institute of the Private Joint Stock Company "Higher education institution

“The Interregional Academy of Personnel Management”, Ukraine.

E-mail: olih.marta@gmail.com

ORCID: https://orcid.org/0000-0002-2699-7684
} 
further development of the country's innovation infrastructure.

The study of the relationship between clustering of the country and the problems of development of its innovation infrastructure, the analysis of the cluster mechanisms in the national innovation system are reflected in the works of such economists as Z. Adamanova (Adamanova, 2012), Yu. Bocharova (Bocharova, 2017), Yu. Fedotova (Fedotova, 2018), L. Fedulova (Fedulova, 2015), L. Pankova, T. Potapenko (Pankova, Potapenko, 2018), M. Porter (Porter, 1998), S. Pyatinkin, T. Bykova (Pyatinkin, Bykova, 2008), N. Potapova (Potapova, 2010), L. Ryneiska (Ryneiska, 2016), I. Shvets (Shvets, 2011), J. Schumpeter (Schumpeter, 2005), S. Sokolenko (Sokolenko, 2004), L. Vasylchenko (Vasilchenko, 2015), Yu. Yukhnovska (Yukhnovska, 2020) and others.

Innovation clusters are considered as an effective mechanism that contributes to the formation of a market infrastructure environment, attracting investment and supporting the operation of small and medium businesses. However, the influence of clustering on the development of the national innovation system, as well as the mechanisms and methodology of the formation and spread of the innovation infrastructure around clusters are insufficiently studied in the scientific literature and require additional research and analysis.

The purpose of the article is to study the role and impact of clustering on self-organization and selfdevelopment of the country's innovation infrastructure.

\section{The essence of clustering in the economic processes}

The process of clustering should be considered from the standpoint of the mechanism of diversified development of regional or national economy, given that the economic cluster itself is a high, but not the final form of economic integration. The presence of diversified clusters allows regional economic systems to maintain their advantage over other regions more prone to renewal and innovation. Diversified clusters are a prerequisite for significant investment and close attention of the government and society, i.e. a cluster becomes a more important unit than a simple sum of its individual businesses. In the process of a diversified cluster development, economic resources come to it from isolated industries that cannot use them as productively as it is possible with diversified partnerships (Vasilchenko, 2015).

Clustering is a set of organizational and economic measures carried out by state, private or public institutions in order to unite enterprises and businesses into clusters, to establish informal relationships between them and to provide network cooperation (Pyatinkin, Bykova, 2008).
A cluster is an organizational unit of technologically interconnected industries located in one region (Porter, 1998). Thus, first, the core of a cluster is created; a number of service companies appear around it and form the cluster infrastructure, which offers various services to the cluster companies on a commercial basis.

Cluster-based economic development is carried out through the introduction of successive stages (Sokolenko, 2004):

1) mobilization stage (stimulation of the interest of implementers);

2) diagnosis stage (assessment of the economy and economic infrastructure);

3 ) cooperation stage (persuasion in the importance of cooperation);

4) implementation stage (implementation of the initiatives of cluster working groups).

The formation of clusters of innovation and research activity is mainly associated with specializing in specific areas, including the creation of new products and technologies. The effectiveness of the results of the cluster depends on the balance of research funding processes and the final costs of their development. The achievement of optimal proportions allows to form territorial zones that combine the scientific and production potential of enterprises with a certain specialization in the innovation areas (Potapova, 2010).

It is important to note that cluster development policy focuses on the microeconomic level. This allows to take into account local characteristics and introduction of targeted measures to accelerate the development and competitiveness of enterprises based not only on existing but also on created factors of production, among which an important place belongs to a highly skilled workforce and developed infrastructure (Fedotova, 2018).

A developed innovation infrastructure is a necessary part of a competitive national economy. It is an array of scientific and technical centers for developers of innovative ideas and proposals, an array of financial assets, production facilities, and an information array:

1. Scientific and technical centers of innovative proposals include, primarily, universities, scientific, research, technical and design institutions, as well as developers of new ideas and innovative proposals, inventors and innovators.

2. The financial array is represented by venture capital and venture banks, which are ready to invest their assets in the production of new goods, equipment, and services.

3. The array of production facilities consists of venture firms, experimental workshops, plants and factories, which provide their production facilities and equipment, offer services for the implementation of innovative projects, production of prototypes and the beginning of industrial production of innovative products. 
4. The information array of the innovation infrastructure is a complex of consulting firms, patent and license bureaus, information agencies and more.

A cluster model of national economy development is a conceptual approach that involves the use of clusters as system-forming elements of a modern market economy, which allows to realize the country's competitive advantages within the international economic space (Pankova, Potapenko, 2018).

\section{Clusters: types and formation principles}

A classic example of a cluster is Silicon Valley in the USA (Martines, 2018). Until the middle of the last century, it was an agricultural area known for its gardens. The center that gave this area the impetus for innovative development was Stanford University in Palo Alto, where innovative ideas and proposals in the field of semiconductors and electronics were researched and developed. The university began to offer its research to companies involved in the introduction of new technological developments in the field of electronics. These ideas were industrially implemented in 1956, when IBM Corporation opened the first large computer plant in San Jose. The infrastructure gradually developed in Silicon Valley, which to this day specializes in servicing hightech enterprises implementing projects in the field of radio electronics and rocketry. New jobs appeared, and the standard of living in the region became one of the highest in the USA. Silicon Valley now includes the range of cities that stretch from San Francisco Bay to San Jose. Thus, the cluster and its infrastructure is an open network formation, which is gradually spreading and is not closed within the initial framework of the regional market.

European cluster policy is based primarily on the European Regional Charter and the Cluster Initiative Greenbook (The Cluster Initiative Greenbook, 2003), which identifies the importance of cluster associations and includes a number of factors necessary for their effective formation. The EU sees cluster policy as a key tool for increasing the competitiveness of industries and regions, strengthening innovation capacity and economic development in the medium and long term.

The classification of clusters according to the direction of the predominant integration ties, by sectors of the economy and types of activity demonstrates the multifaceted nature of their functioning. Due to this, clusters can be considered universal tools for economic development (Ryneiska, 2016).

There are vertical and horizontal types of clusters. Vertical clusters are based on "buyer - seller" relationships. Horizontal clusters include industrial enterprises that share markets for final products, use the same technologies, production processes or require the same natural resources (Porter, 1998).
Taking into account the specifics of the industry, there are: discrete clusters (containing enterprises that produce products and related services, consist of discrete components, in particular, enterprises that develop around assembly and construction organizations); process clusters (formed by enterprises belonging to process industries, such as agriculture, food industry and others); innovation and creative clusters (developing in the fields of information technology, biotechnology, new materials, as well as in the service sectors related to business, creative and animation activities); tourism clusters (formed on the basis of tourism assets of the region and consist of enterprises of various sectors related to tourist services, such as tour operators, hotels, restaurant business, souvenir manufacturers, transport companies and others); transport and logistics clusters (contain a set of infrastructure and companies specializing in storage, escort and delivery of passengers and goods) (Yukhnovska, 2020), (Shvets, 2011).

Forming a cluster policy, state authorities of developed countries distinguish the following types of clusters: competitive (the priority is leadership in competition); strategic (economic recovery of the backward region); emerging (with a high rate of development); potential (with a high level of competence, which may ensure the recovery of the region's economy); stabilizing (contribute to economic diversification and jobs creation) (Adamanova, 2012).

Thus, the intensification of entrepreneurship in clusters is carried out through the concentration of business activity and inter-sectoral cooperation. Vertical cluster associations are formed on the basis of synergy of enterprises, institutions, organizations, and individuals that are heterogeneous in terms of activity and form of ownership.

\section{A cluster's hub as an element of interconnection of innovation infrastructure entities}

Defining the critical point of the enemy's infrastructure, the nineteenth-century Prussian military theorist and historian Carl Clausewitz (Clausewitz, 1873) proposed to find a center of mass a "hub", a "central point" of the armed forces, economy or infrastructure of the state, the center of all resources and events. An attack on such a center of the enemy can ensure victory in a military conflict. However, it is possible to consider hubs in the economic aspect as well. For example, the creation of such a hub as a center for the production of competitive products will serve as a basis for grouping around it of the area of service organizations for infrastructure purposes and their further integration into the cluster.

A cluster's hub should be understood as a key node that ensures the connection and interaction of all subjects of the innovation infrastructure, without 
which a hub cannot function or its capabilities will be significantly limited.

A hub can be seen as the beginning, the starting point of the future network structure - a cluster and the emergence of a new form of organization of interaction between economic entities in a particular region. The most innovatively active company, research organization or higher education institution can become a starting point, a hub, which is combined with a number of carefully selected, interconnected in the technological chain and interested in economic symbiosis business partners.

Among the conditions that ensure the economic development of the country in the era of markets globalization, an important role is played by the processes of the widespread use of innovations, innovative activity of enterprises, general development of the innovation infrastructure, communication with scientific and educational institutions, and constant improvement of the qualification level of personnel, their knowledge, skills and abilities. Innovative activity is a characteristic feature of most existing clusters and their infrastructural environment.

The innovation infrastructure, like other large network structures (for example, the Internet, economic and social network structures, etc.), has a complex internal organization and under certain conditions can become self-organizing on the basis of interaction and widespread interference of the network of hubs, clusters, centers of economic development and innovative services. In the military economy, the basic element that is necessary for the self-organization of such a system is energy. It can be physical energy (a large number of people, equipment, industrial facilities, special structures, communication systems, new types of equipment and technologies) or psychological energy (willpower and strength of spirit of people, their dedication, knowledge, capabilities and abilities). The potential energy of money, financial and innovation potential of the region or country can be added to the physical energy.

According to the theory of self-organizing networks, which include an innovative infrastructure, initially, the number of such development centers, hubs, and clusters may be insignificant. As the amount of physical and psychological energy increases, they can grow and expand effectively in accordance with current economic laws and legal regulations. This allows unstructured elements to form arrays of cluster groups as centers of innovation development are the subjects of innovation infrastructure and self-organizing in different regions of the country. A certain mass of commercial structures accumulates around the clusters and offers their services, necessary for the implementation of the innovative projects at different stages of this process, to not only the enterprises of this cluster, but also to other innovative enterprises that have the nearest location. That is, the innovation infrastructure of clusters is gradually growing into the innovation infrastructure of the country.

Therefore, a cluster is a sectoral, territorial, voluntary association of business structures that work closely with scientific (educational) institutions, non-government organizations and local authorities to increase the competitiveness of their products and promote economic and innovative development of the territory or region (Kniazevych, 2018).

A cluster is a contractual association of legal entities and individuals without the creation of a new legal entity. It should be emphasized that clustering has a voluntary nature. Entrepreneurs, based on their commercial considerations, come to believe and agree on the need and mutual benefit of such an association. Only in this case, there is a surge of physical and, most importantly, psychological energy based on personal and commercial interest and enthusiasm needed for the hub formation, which through the activity of the founders extends its sphere of influence to other organizations and can grow into a cluster. A cluster hub can be one or more companies that are able to produce quality, competitive products and are market leaders.

The application of the cluster approach is one of the most effective mechanisms of structural development of the economy. Depending on the innovation activity, network structures can be of two types: with a center (hub) or, less often, without a clear center. The positive side of a cluster is that its members do not compete directly with each other, but operate in different market segments (Tyutyushev, Gasanov, Vasechko, 2011).

Clusters are varieties of large business-type networks concentrated in a geographically defined area. A cluster usually includes manufacturers of certain products and services, suppliers of raw materials, equipment and technology, and commercial structures. The basics of cooperation, interaction and inter-network relations between the organizations that are part of the cluster are determined by the relevant agreements. The most successful innovation clusters are formed in areas, where there is an innovative breakthrough in the field of production, technology, or services.

A hub provides an innovative initiative and the main focus of innovation. Other members of the cluster gather around the hub, performing their functions in accordance with the leadership of the hub. The innovation infrastructure develops around the core of the cluster. It includes independent organizations, enterprises, companies and institutions, branches of organizations and enterprises, and private professionals, who offer their services in the implementation of innovation activities to the cluster entities.

Innovative orientation of activity, which is characteristic for clusters, causes the need to include in the general network of the cluster organizations that create an auxiliary infrastructure around the production center. Compared to other types of business networks, 
clusters bring together a wider range of innovation participants. The innovation infrastructure of the cluster may include research and design institutes, universities, information agencies, standardization centers, trade associations, agencies that provide specialized training and retraining, and grant-making funds. The infrastructure shell of the cluster provides selection, development and implementation of innovative projects.

A cluster brings together independent and informally connected companies and institutions that can simultaneously cooperate with other organizations that are not part of the cluster. A cluster is a concentration of industrial and other facilities that receive economic benefits due to their close proximity to each other. However, all subjects of innovation infrastructure of one cluster can actively expand the area of their activity and offer their services on commercial terms, both for a number of neighboring clusters and for individual enterprises implementing innovation projects. The impact of the innovation infrastructure of neighboring clusters can extend the scope of their services to the entire region, and with the further clustering of regions to the whole country. Therefore, clustering of regions can ensure the overall development of the country's innovation infrastructure.

\section{Conclusions}

Clusters and an innovation infrastructure, which appears around them, form an attractive basis for innovation, investment flows, and development of small and medium enterprises. This is a kind of a large innovation-entrepreneurial network, which is especially effective in times of crisis.

The application of the cluster approach and the spread of the processes of clustering of the economy are among the most effective mechanisms for the structural development of national and regional innovation systems.

The gradual increase in the number of cluster structures and their concentration in different regions of the country will lead to the creation around them of a network of business entities that self-organize on a commercial basis and specialize in providing services for innovative projects for a wide range of innovative enterprises. Thus, the growth of a network of similar structures specializing in innovation services will serve as a basis for self-organization of the system of the active innovation infrastructure of the whole country. Self-organization is a synergy process of ordering the chaotic action of the elements of the system and their transition to a qualitatively new level due to internal factors, without any external influence. However, this does not mean that these structures are unmanageable. They are controlled not by direct commands but by changing the boundary parameters. A state regulates the boundary conditions of activity for the subjects of an innovation infrastructure, clusters, which independently, based on commercial considerations, self-organize under the influence of market mechanisms and expand their services to all regions, forming an integrated innovation infrastructure.

\section{References:}

Adamanova, Z. O. (2012). Innovation clusters in national economic systems: world experience and possibilities of its adaptation in the conditions of Ukraine. Formation of market relations in Ukraine. Vol. 5/1. P. $162-163$. (in Ukrainian)

Bocharova, Yu. G. (2017). The concept of formation and strategy of innovation infrastructure development. Kryvyi Rih: Chernyavsky. (in Ukrainian)

Clausewitz, C. (1873) [1832]. On War [Vom Krieg]. Translated by Graham, J.J. London: N. Trübner \& Co.

Fedotova, Yu. V. (2018). Clustering of the economy as a direction of overcoming the disproportion of regional development. Young scientist. Vol. 1(1). P. 545-549. (in Ukrainian)

Fedulova, L. I. (2015). European Union clustering policy. Bulletin of Khmelnytsky National University. Economic sciences. Vol. 3(2). P. 144-148. (in Ukrainian)

Goncharenko, M. F., \& Horbach, L. M. (2018). Knowledge economy as a stage in the development of post-industrial society. Problems of modern science. Namur, Belgium. P. 5-10. (in Ukrainian)

Holovatyi, M. (2015). The state and society: The conceptual foundations and social interaction in the context of formation and functioning of states. Economic Annals. Vol. XXI, P. 9-15.

Kniazevych, A. (2018). Management of infrastructure support of innovative development of economy. Rivne: Volyns'ki oberehy. (in Ukrainian)

Kniazevych, A., Kyrylenko, V., \& Golovkova, L. (2018). Innovation infrastructure of Ukraine: assessment of the effectiveness of the action and ways of improvement. Baltic Journal of Economic Studies. Vol. 4. No. 1 January. P. 208-218. DOI: https://doi.org/10.30525/2256-0742/2018-4-1-208-218

Kotlyarov, V. O. (2016). Features of economic and investment integration of Ukraine. Regional problems of development of territorial systems: theory, practice, prospects. Part 2. P. 117-120. (in Ukrainian)

Martines, A. H. (2018). Chaos in Silicon Valley [Khaos u Kremniievij dolyni], Kyiv: Nash format. (in Ukrainian) Pankova, L. I., \& Potapenko, T. P. (2018). Formation of cluster models of national economies on the basis of stimulating regional development. Economics and organization of management. Vol. 2(30). P. 47-56. 
Porter, M. (1998). Clusters and the New Economics of Competition. World Economy. Vol. 76. NovemberDecember. P. 293-317.

Pyatinkin, S. F., \& Bykova, T. P. (2008). Development of clusters: essence, actual approaches, foreign experience. Minsk: Theseus. (in Russian)

Potapova, N. A. (2010). Clustering of economic regions of Ukraine in terms of innovation and research. Bulletin of the National University „Lviv Polytechnic” Problems of Economics and Management. Vol. 684. P. 33-39. (in Ukrainian)

Ryneiska, L. S. (2016). Clusters in the modern global economy. Efektyvna ekonomika. Available at: http://www.economy.nayka.com.ua/?op=1\&z=4971 (accessed 5 May 2021). (in Ukrainian)

Shvets, I. Yu. (2011). Spatio-regional clustering of tourist complex. Marketing and Management of Innovations. Vol. 2. P. 65-73. (in Russian)

Schumpeter, J. (2005). Development. Journal of Economic Literature. Vol. 43. No. 1. P. 108-120.

Senyshyn, O., \& Olikhovska, M. (2018). Using the world experience of developed countries in the formation of directions for improving the process of development and implementation of government targeted programs for natural environmental protection. Baltic Journal of Economic Studies. Vol. 4. No. 5. December. P. 305-314. DOI: https://doi.org/10.30525/2256-0742/2018-4-5-305-314

Sokolenko, S. (2004). Clusters in the global economy. Kyiv: Logos. (in Ukrainian)

The Cluster Initiative Greenbook: New Findings on the Process of Cluster-Based Economic Development (2003). $93 \mathrm{p}$.

Tyutyushev, A. P., Gasanov, M. A., \& Vasechko, D. Yu. (2011). Clusters as innovative economic structures of the network type. Bulletin of Tomsk State Pedagogical University. Vol. 12(114). P. 121-127. (in Russian)

Vasilchenko, L. S. (2015). Clustering as an innovative form of diversification of regional economic systems. Global and National Economic Problems. Vol. 5. P. 667-670. (in Ukrainian)

Vykliuk, M., Mikhailishin, R., Kundytskyj, O., Senyshyn, O., Prokopenko, N., \& Olikhovskyi, V. (2020). Conceptual basis of the state's tax security model. Management Theory and Studies for Rural Business and Infrastructure Development. Vol. 42. No. 3. P. 303-315.

Yukhnovska, Yu. O. (2020). Formation and development of potential of the tourism industry: regional aspect. Zaporizhzhia: Prosvita. (in Ukrainian) 